\title{
Qualidade de sementes de Lolium multiflorum tetraploide comercializadas em Santa Catarina
}

\section{Quality of Lolium multiflorum tetraploide seeds marketed in Santa Catarina}

\author{
Ricardo MiottoTernus $^{1,2,3}$; Jerffeson Araujo Cavalcante ${ }^{3 *}$; Ana Carolina Weiss ${ }^{4}$; Paula da Silva Folquini ${ }^{4}$; Jonas Bloemer ${ }^{4}$; \\ Geri Eduardo Meneghello
}

Resumo: Na região Sul do Brasil, no período do inverno o azevém (Lolium multiflorum Lam) se torna fundamental para a formação de pastagens. No entanto, o uso e a comercialização de sementes de azevém tetraploide têm crescido em relação aos diploides, devido, principalmente, a qualidade superior de suas sementes. O objetivo do trabalho foi avaliar a qualidade das sementes de azevém tetraploide, comercializadas no Estado de Santa Catarina. Foram utilizados seis lotes de sementes de azevém tetraploide da cultivar Barjumbo, oriundos de diferentes estabelecimentos comerciais do Estado de Santa Catarina. Cada lote de semente foi obtido a partir de coleta oficial. Buscaram-se lotes de sementes da categoria certificada, sendo dois lotes de cada país produtor (Argentina, Brasil e Uruguai). Avaliou-se a qualidade física e fisiológica a partir dos testes de pureza física, massa de mil sementes, teste de germinação, primeira contagem de germinação, comprimento da parte aérea e da raiz e massa seca da área e da raiz. Os resultados demonstram que $100 \%$ dos lotes analisados atendem os padrões legais de pureza física e germinação para a comercialização de sementes, independente da origem. Para o teste de germinação os resultados obtidos foram $27 \%$ superiores ao padrão legal. Os lotes de sementes de azevém tetraploides nacionais comercializados em Santa Catarina, mesmo apresentando-se dentro dos padrões legais para os testes de pureza física e germinação, apresentaram menor vigor quando comparados aos lotes oriundos da Argentina e Uruguai.

Palavras-chave: Azevém; Comercialização; Fiscalização de sementes; Controle de qualidade.

Abstract: In the southern region of Brazil, during the winter period ryegrass becomes essential for pasture formation. The use and commercialization of tetraploid ryegrass seeds has grown in relation to diploids, mainly due to the superior quality of their seeds. The objective of this work was to evaluate the quality of tetraploid ryegrass seeds commercialized in the State of Santa Catarina. Six plots of tetraploid ryegrass seeds of the Barjumbo cultivar from different commercial establishments in the State of Santa Catarina were used. Each batch of seed was obtained from official collection. Lots of seeds of the certified category were searched, being two lots from each producing country (Argentina, Brazil and Uruguay). The physical and physiological quality was evaluated from the physical purity tests, mass of one thousand seeds, germination test, first germination count, shoot and root length and dry mass of the area and root. The results show that $100 \%$ of the analyzed lots meet the legal standards of physical purity for the commercialization of seeds. For the germination test the results obtained are $27 \%$ higher than the legal standard. The plots of tetraploid ryegrass seeds commercialized in Santa Catarina were within the legal standards for the physical purity and germination tests, while the other criteria showed inferior performance when compared to the plots of Argentina and Uruguay.

Key words: Ryegrass; Commercialization; Seed inspection; Quality control.

\footnotetext{
*Autor para correspondência

Recebido para publicação em 11/11/2016; aprovado em 03/02/2017

${ }^{1}$ Msc. Professor do curso de Agronomia, Centro Universitário Barriga Verde - UNIBAVE. E-mail: ricardomiter@gmail.com

${ }^{2}$ Companhia Integrada de Desenvolvimento Agrícola de Santa Catarina - CIDASC. E-mail: miotto@ cidasc.sc.gov.br

${ }^{3}$ Doutorando do Programa de Pós-Graduação em Ciência e Tecnologia de Sementes - UFPel. E-mail: jerffeson_agronomo@hotmail.com

${ }^{4}$ Graduando em Agronomia, Centro Universitário Barriga Verde. E-mail: acarolinaw@ hotmail.com; folquini@hotmail.com; jonas.bloemer@hotmail.com

${ }^{5}$ Dr.Eng.Agrônomo do Programa de Pós-Graduação em Ciência e Tecnologia de Sementes - UFPel. E-mail: gmeneghello@gmail.com
} 


\section{INTRODUÇÃO}

As culturas de verão, como soja, milho, arroz, feijão e sorgo ocupam, na região Sul do Brasil, a maior parte da área cultivada, com cerca de 13,5 milhões de hectares. Quando comparadas com as culturas de inverno, a área cultivada não chega a três milhões de hectares. Por essa razão, se faz necessário à busca de alternativas para este período, uma delas é a utilização de espécies que possam ser utilizadas como cobertura de solo e produção de forragem para alimentar os animais (FONTANELI et al., 2012).

Dentre essas espécies, o azevém (Lolium multiflorum Lam.) é uma das recomendadas para o período de inverno na região Sul, com o propósito de suprir esta sazonalidade na oferta de pastagens (MARCHESAN, 2014). Contudo, esta espécie apresenta crescimento lento em baixas temperaturas, principalmente nos meses de junho e julho, apesar de ser uma planta de clima frio, aumenta sua produção de matéria seca em temperaturas mais elevadas na primavera (FLOSS, 1988; ROSO et al., 1999). Além disso, segundo Flores et al. (2008), o azevém pode ser utilizado isoladamente, em consórcio com outras espécies, atuando como melhoradora de pastagens naturais ou como cobertura do solo, além de possuir grande variabilidade dentro da espécie e boa produção de forragem ao longo do ciclo.

Sendo uma Poaceae forrageira de clima temperado, amplamente difundida no sul do Brasil, o azevém ainda vem mantendo sua produção de sementes em áreas destinadas ao pastejo e posteriormente diferidas para a colheita de sementes. Esse sistema de manejo obtém-se rendimentos de sementes próximos a $500 \mathrm{~kg} \mathrm{ha}^{-1}$, embora em condições experimentais tenham sido registrados valores de até $1200 \mathrm{~kg}$ ha $^{-1}$ (MEDEIROS; NABIGER, 2001). Além do baixo rendimento médio, as sementes produzidas com o manejo descrito são, via de regra, de baixa qualidade fisiológica (MAIA, 1995).

Contudo, a maioria dos produtores brasileiros de sementes multiplicam variedades diploides, denominado azevém comum. Neste contexto, Ternus et al. (2016) analisando dados da coleta oficial de amostras de sementes realizadas entre 2013-2015, no Estado de Santa Catarina, verificaram que os lotes de sementes de azevém, apresentaram índice de conformidade de $34 \%$ para o teste de germinação e $38 \%$ para a pureza.

Por outro lado, alguns produtores vêm utilizando as cultivares tetraploides, que apresentam algumas características distintas, como rápida produção inicial e alta produção de massa total, além de apresentarem um ciclo vegetativo mais longo em comparação as cultivares diploides (OLIVEIRA et al., 2014). Atualmente, segundo Blount (2012), estão disponíveis no mercado inúmeras variedades tetraploides, que por possuir essa característica, tende a uma maior produção de forragem e folhas maiores e com cores mais escuras que os diploides.

Ternus et al. (2016) verificaram aumento de $20 \%$ na comercialização de sementes de azevém tetraploide nos estabelecimentos comerciais de Santa Catarina no ano de 2015, quando comparado ao ano anterior. Segundo os mesmos autores, a ascensão comercial deste tipo de material é devida, principalmente, pela qualidade superior de suas sementes, destacando-se o aspecto fisiológico, adaptação as condições ambientais do estado e alto desempenho produtivo.
Diante do exposto, o presente trabalho teve por objetivo avaliar a qualidade de lotes de sementes de azevém tetraploide oriundo de diferentes países e comercializadas no Estado de Santa Catarina.

\section{MATERIAL E MÉTODOS}

O trabalho foi conduzido no Laboratório Didático de Análise de Sementes do Departamento de Fitotecnia, pertencente a Faculdade de Agronomia Eliseu Maciel da Universidade Federal de Pelotas, Campus Capão do Leão, Rio Grande do Sul.

Foram utilizados seis lotes de sementes de azevém tetraploide da cultivar Barjumbo, oriundos de diferentes estabelecimentos comerciais do Estado de Santa Catarina, sendo que cada lote de semente foi obtido a partir do excedente de coleta oficial de amostra de sementes, realizada por Fiscal Estadual Agropecuário (FEA), conforme metodologia específica de amostragem prevista nas Regras para Análise de Sementes (RAS), cada lote composto por no mínimo por 30 sub-amostras em função da sua representatividade. Durante as coletas buscaram-se lotes de sementes da categoria certificada ( $\mathrm{C} 1$ e $\mathrm{C} 2)$, sendo dois lotes de cada país produtor (Argentina, Uruguai e Brasil). Portanto, a partir do preparo da amostra média e duplicata, destinou-se uma quantidade de sementes igual àquela prevista nas RAS para avaliar qualidade física e fisiológica, a partir dos seguintes testes:

Pureza física (PF): realizada segundo prescrições das Regras para Análise de Sementes (BRASIL, 2009) e os resultados expressos em porcentagem de sementes puras.

Massa de mil sementes (MMS): Foram utilizadas oito subamostras de 100 sementes para cada repetição, provenientes da porção semente pura de cada lote. As sementes foram contadas manualmente e em seguida pesadas em balança analítica com precisão de 0,0001g (BRASIL, 2009). Os resultados foram expressos em gramas.

Teste de germinação (GER): foi conduzido com oito repetições, utilizando-se como substrato rolo de papel para germinação $\left(\right.$ germitest $^{\circledR}$ ), umedecido com 2,5 vezes o seu peso com água destilada (BRASIL, 2009). As avaliações das plântulas normais foram realizadas aos sete dias após a semeadura (DAS) e os resultados expressos em porcentagem de germinação.

Primeira contagem da germinação (PCG): foi realizada aos três dias a partir da semeadura, sendo conduzido juntamente com o teste de germinação sendo os resultados expressos em porcentagem de plântulas normais (BRASIL, 2009).

Comprimento da parte aérea (CPA) e da raiz (CR): para a determinação do comprimento, 20 sementes foram distribuídas em duas linhas (10 sementes linha $\left.{ }^{-1}\right)$ traçadas no terço superior de duas folhas de papel germitest, previamente umedecidas em água e soluções salinas com quantidade equivalente a 2,5 seu peso seco (NAKAGAWA, 1999). Posteriormente, foram confeccionados rolos sendo os mesmo acondicionados em germinadores com temperatura de $25{ }^{\circ} \mathrm{C}$. Após três dias, 10 plântulas foram selecionadas ao acaso das oito repetições. A medição do comprimento da parte aérea e das raízes foi obtida com auxílio de um paquímetro de precisão e os resultados expressos em $\mathrm{cm}_{\text {plântula }}{ }^{-1}$.

Massa seca da parte aérea (MSPA) e da raiz (MSR): foi obtida na primeira contagem de germinação, pela média 
de 10 plântulas selecionadas para as medidas de comprimento. A determinação da massa seca das plântulas foi obtida gravimetricamente em estufa a $70 \pm 1^{\circ} \mathrm{C}$ até massa constante, sendo os resultados expressos em gramas plântula 1

O delineamento experimental adotado foi o inteiramente casualizado (DIC) com oito repetições para cada lote de semente. Após tabulação dos dados, foram verificadas as pressuposições da análise da variância, e sendo estas contempladas, procedeu-se a análise de variância (ANOVA). Quando significativos pelo teste $\mathrm{F}$, as médias foram comparadas pelo teste de Tukey a $5 \% \quad(p \leq 0,05)$ de probabilidade.

\section{RESULTADOS E DISCUSSÃO}

Na Tabela 1 são apresentados os dados relacionados aos testes de pureza física e germinação. Constatou-se que $100 \%$ dos lotes analisados atendem os padrões legais para a comercialização de sementes de azevém, que, no Brasil, é no mínimo de $97 \%$ de pureza física. No teste de germinação percebeu-se que os resultados obtidos, independente da origem, foram, em média, $27 \%$ superiores ao padrão previsto para germinação que é de $70 \%$. Por outro lado, Ternus et al. (2016) analisando 135 amostras de azevém diploide no período de 2013 a 2015 verificaram um índice de conformidade de 34 e $38 \%$ para os testes de pureza e germinação, respectivamente. Este desempenho superior dos materiais importados pode ser fruto das exigências impostas, relacionadas à qualidade física e fisiológica que são aferidas no momento da entrada das sementes no território nacional.

É importante ressaltar que a informação disponível na literatura concernente a dados sobre a fiscalização de sementes de azevém tetraploides no Brasil, bem como a análise da qualidade de diferentes lotes de sementes, ainda é escassa ou inexistente. Porém, diversos trabalhos têm demonstrado a ineficiência do setor produtivo de sementes de forrageiras de clima temperado no Brasil, identificando problemas tanto no processo de produção das sementes como na manutenção da sua qualidade até o ato de comercialização.

Holbig et al. (2011), ao avaliar a qualidade física e fisiológica de sementes de aveia preta e azevém comercializadas em duas regiões do estado do Rio Grande do Sul, observaram que as sementes de azevém comercializadas nos municípios de Pelotas e Alegrete possuem baixa qualidade fisiológica e pureza física abaixo do mínimo exigido pela legislação. $\mathrm{O}$ mesmo foi observado por Belmonte (2002), quando avaliou a qualidade física de sementes fiscalizadas de aveia branca, aveia preta, azevém e milheto, verificou que todos os lotes de azevém analisados apresentaram pureza física inferior a 97\%. Tais resultados reafirmam o histórico negativo da qualidade de sementes de azevém comercializadas no Rio Grande do Sul.

Tabela 1. Pureza física e germinação de sementes de diferentes lotes de azevém da cultivar Barjumbo oriundas de diferentes países, comercializadas no Estado de Santa Catarina

\begin{tabular}{|c|c|c|c|c|c|c|}
\hline \multirow{2}{*}{ Origem } & \multicolumn{3}{|c|}{ Pureza Física (\%) } & \multicolumn{3}{|c|}{ Germinação (\%) } \\
\hline & Lote 1 & Lote 2 & Média & Lote 1 & Lote 2 & Média \\
\hline Argentina & 99,2 & 99,6 & $99,4 \mathrm{a}$ & 95 & 93 & $94 \mathrm{~b}$ \\
\hline Uruguai & 99,2 & 99,7 & $99,4 \mathrm{a}$ & 98 & 98 & $98 \mathrm{a}$ \\
\hline Brasil & 98,5 & 98,3 & $98,4 \mathrm{~b}$ & 90 & 89 & $89 \mathrm{c}$ \\
\hline $\mathrm{CV}$ & & & 0,54 & & & 1,44 \\
\hline
\end{tabular}

Médias seguidas pela mesma letra minúscula na coluna não diferem entre si pelo teste de Tukey a 5\% de probabilidade.

Em relação a massa de mil sementes, os lotes de sementes oriundos do Uruguai e da Argentina apresentaram desempenho médio superior quando comparados aos lotes nacionais (Tabela 2). Este fato pode estar relacionado com a colheita antecipada do azevém, reduzindo o tempo para o acúmulo de fotoassimilados nas sementes. O retardamento ocorre, principalmente, por duas maneiras, uma em virtude da preferência do Rio Grande do Sul pela exploração de lavouras de soja e milho, como a semeadura dessas culturas é no início da primavera faz com que as sementes de azevém sejam colhidas antecipadamente (GARCIA; MENEZES 1999). Outra prática utilizada que pode influenciar na redução da massa de mil sementes é o uso à dessecação química do azevém visando antecipar a colheita de sementes o que tem levado a seleção de plantas de ciclo precoce, com desenvolvimento fisiológico mais curto (MAIA, 1995).

É importante salientar que o Estado de Santa Catarina é essencialmente um consumidor de sementes, sendo abastecido principalmente pelo Rio Grande do Sul, ocupando 91\% do comércio de sementes de azevém (TERNUS et al., 2016).

Ainda na Tabela 2, observou-se que as médias dos lotes de sementes do Uruguai e da Argentina, apresentaram peso maior que o dobro em relação a médias dos lotes de sementes produzidos no Brasil. Hessel et al. (2012), destaca que sementes com menor peso geralmente está intimamente relacionado com menor viabilidade e vigor destas.

Para a primeira contagem de germinação (Tabela 2), as médias dos lotes de sementes uruguaias apresentaram-se mais vigorosos, apresentando-se 11,6 e 18,5\% superiores aos lotes argentinos e brasileiros, respectivamente, sendo os lotes de sementes de origem brasileira com menor qualidade entre todos. Para a emergência (Tabela 2), observou-se que os lotes importados não diferiram entre si, porém, apresentaram desempenho médio $21 \%$ superior aos lotes nacionais disponíveis para comercialização em território catarinense. Segundo Maia (1995), produção e qualidade de sementes, alcançados em pesquisa e por produtores em diferentes regiões do Rio Grande do Sul, indicam que o azevém apresenta excelente potencial, atingindo rendimentos de cerca de $1.000 \mathrm{~kg} \mathrm{ha}^{-1}$ de sementes puras com vigor mínimo de $90 \%$. Além disso, segundo o mesmo autor, no estado do Rio Grande do Sul se manejam os campos destinados à produção de sementes de azevém com animais, e isso provoca uma interferência na produtividade e na qualidade de semente. 
Tabela 2. Massa de mil sementes (MMS), primeira contagem de germinação (PGC) e emergência de sementes de diferentes lotes de azevém da cultivar Barjumbo oriundas de diferentes países, comercializadas no Estado de Santa Catarina

\begin{tabular}{cccccccccc}
\hline \multirow{2}{*}{ Origem } & \multicolumn{3}{c}{ MMS $(\mathrm{g})$} & \multicolumn{3}{c}{ PCG $(\%)$} & \multicolumn{3}{c}{ Emergência $(\%)$} \\
\cline { 2 - 10 } & Lote 1 & Lote 2 & Média & Lote 1 & Lote 2 & Média & Lote 1 & Lote 2 & Média \\
\hline Argentina & 4,8 & 4,0 & $4,4 \mathrm{a}$ & 91 & 81 & $86 \mathrm{~b}$ & $83 \mathrm{a}$ & 85 & $84 \mathrm{a}$ \\
Uruguai & 5,0 & 4,3 & $4,6 \mathrm{a}$ & 95 & 97 & $96 \mathrm{a}$ & $84 \mathrm{a}$ & 88 & $86 \mathrm{a}$ \\
Brasil & 1,9 & 1,9 & $1,9 \mathrm{~b}$ & 83 & 79 & $81 \mathrm{c}$ & $71 \mathrm{~b}$ & 69 & $70 \mathrm{~b}$ \\
\hline CV & & 5,63 & & & 2,36 & 5,31 \\
\hline
\end{tabular}

Médias seguidas pela mesma letra minúscula na coluna não diferem entre si pelo teste de Tukey a 5\% de probabilidade.

Os lotes nacionais apresentaram desempenho inferior quando comparados àqueles importados, tanto para o comprimento de raiz quanto de parte aérea (Tabela 3). Notouse que os materiais importados foram 50 e 37,5\% superiores para estas variáveis, respectivamente. Diante desses resultados, é importante ressaltar que plântulas normais ou partes desta que apresentam maiores comprimentos, são indicativos de elevado vigor das sementes que a originarão (NAKAGAWA, 1999). Assim, sementes mais vigorosas podem proporcionar melhores condições intrínsecas para o estabelecimento das plântulas no campo.

A massa seca da raiz e da parte aérea, foi observado o mesmo comportamento das variáveis de comprimento, sendo os lotes oriundos do Brasil com menor acúmulo de massa seca, tanto da raiz como da parte aérea. Ainda na Tabela 3, foram verificados incrementos médios de 1,08 e 2,20, para Argentina e Uruguai, respectivamente, vezes superiores quando comparados com lotes nacionais.

Correlacionando os resultados da germinação (Tabela 1) com os de massa seca (Tabela 3), constatou-se que, mesmo a germinação dos lotes, principalmente os de origem nacional, apresentarem germinação acima do exigido pelos padrões legais de comercialização de sementes no Brasil, estas acumularam menor conteúdo de massa seca quando comparados aos lotes oriundos da Argentina e do Uruguai. Porém, no Brasil e principalmente nos estados do Sul, a produção de sementes de azevém apresenta problemas na condução dos campos, como foi destacado nesse trabalho, e isso pode ser um forte indicativo do baixo vigor das sementes nacionais, sendo que, dentre os fatores que influenciam qualidade das sementes dão-se destaque para: qualidade fisiológica inicial da semente, vigor da planta-mãe, condições climáticas durante a maturação, danos mecânicos, durante e após a colheita, ação de microrganismos e insetos, condições de secagem, adequado teor de água, umidade relativa do ar, temperatura de armazenamento, tipos de embalagem e duração do armazenamento (CARVALHO; NAKAGAWA, 2012). Contudo, tais fatores podem não comprometer a germinação, porém, o vigor das sementes pode ser seriamente diminuído ao longo do seu processo de maturação e posterior maturidade fisiológica.

No entanto, o teste de germinação pode superestimar o potencial fisiológico das sementes por não avaliar as alterações fisiológicas, bioquímicas, físicas e citológicas relacionadas ao processo de deterioração, não permitindo diferenciar no campo e no armazenamento lotes de sementes quanto ao vigor (ABRANTES et al., 2010).

Tabela 3. Comprimento da raiz, comprimento da parte aérea e massa seca da raiz e da parte aérea de plântulas de azevém da cultivar Barjumbo oriundas de diferentes países, comercializadas no Estado de Santa Catarina.

\begin{tabular}{ccccccc}
\hline \multirow{2}{*}{ Origem } & \multicolumn{3}{c}{ Comprimento da raiz $(\mathrm{cm})$} & \multicolumn{3}{c}{ Comprimento da parte aérea $(\mathrm{cm})$} \\
\cline { 2 - 6 } & Lote 1 & Lote 2 & Média & Lote 1 & Lote 2 & Média \\
\hline Argentina & 8,6 & 9,6 & $9,1 \mathrm{a}$ & 8,6 & 7,8 & $8,2 \mathrm{a}$ \\
Uruguai & 8,7 & 8,4 & $8,55 \mathrm{a}$ & 7,8 & 8,9 & $8,35 \mathrm{a}$ \\
Brasil & 6,2 & 6,6 & $6,4 \mathrm{~b}$ & 5,5 & 5,5 & $5,5 \mathrm{~b}$ \\
\hline CV $(\%)$ & \multicolumn{3}{c}{ Massa seca da parte aérea $(\mathrm{g})$} \\
\hline \multicolumn{3}{c}{ Massa seca da raiz $(\mathrm{g})$} \\
\hline Argentina & 0,6 & 5,61 & \multicolumn{5}{c}{1,01} \\
Uruguai & 0,6 & 0,6 & $0,65 \mathrm{a}$ & 1,4 & 1,1 & $1,19 \mathrm{a}$ \\
Brasil & 0,3 & $0,60 \mathrm{a}$ & 1,3 & 0,5 & $0,50 \mathrm{~b}$ \\
\hline CV $(\%)$ & 0,3 & $0,30 \mathrm{~b}$ & 0,5 & & 14,95 \\
\hline
\end{tabular}

Médias seguidas pela mesma letra minúscula na coluna não diferem entre si pelo teste de Tukey a 5\% de probabilidade.

É importante ressaltar que a evolução do controle da qualidade de sementes no Brasil, é fruto do aprimoramento da legislação brasileira em torno da produção, análise laboratorial, comercialização de sementes de alta qualidade e de novas técnicas de produção desenvolvidas pela pesquisa pública e privada. Este compromisso com a qualidade é válido na medida em que a comercialização e a utilização de sementes de qualidade proporcionam rápido estabelecimento do estande, até mesmo em condições adversas; desenvolvimento uniforme de plântulas; resistência a insetos, doenças, herbicidas e maturação uniforme de plantas, garantindo alta produtividade e lucratividade (TERNUS et al., 2016).

\section{CONCLUSÕES}

Os lotes de sementes de azevém tetraploides comercializados em Santa Catarina apresentaram-se dentro dos padrões legais vigentes para os testes de pureza física e germinação. 
Para as análises de vigor, os lotes nacionais apresentaram desempenho inferior quando comparados aos lotes provenientes da Argentina e Uruguai.

\section{REFERÊNCIAS}

ABRANTES F. L.; KULCZYNSKI, S. M.; SORATTO, R. P.; BARBOSA, M. M. M. Nitrogênio em cobertura e qualidade fisiológica e sanitária de sementes de painço (Panicum miliaceum L.). Revista Brasileira Sementes, Londrina, v. 32, n. 3, p. 106-115, 2010.

BELMONTE, P. B. A. Qualidade física das sementes fiscalizadas de aveia branca (Avena sativa L.) aveia preta (Avena strigosa Schreb), azevém-anual (Lolium multiflorum Lam.) e milheto (Pennisetum americanum L. Reeke) comercializadas na safra 2001/2002 no estado do Rio Grande do Sul. 2002. 25f. Dissertação (Mestrado em Ciência e Tecnologia de Sementes) - Universidade Federal de Pelotas, Pelotas, 2002.

BLOUNT, A. R.; PRINE. G. M.; CHAMBLISS, C. G. Annual ryegrass. Tampa's: Agronomy Department, Florida Cooperative Extension Service, Institute of Food and Agricultural Sciences, University of Florida. 2012.

BRASIL, Regras para análise de sementes. Ministério da Agricultura e Reforma Agrária. SNDA/DNDV/CLAV, Brasília, p. 365, 2009.

CARVALHO, N. M.; NAKAGAWA, J. Sementes: ciência, tecnologia e produção. 4. ed. Jaboticabal: FUNEP/UNESP, 2012. 588p.

FONTANELI, R. S.; SANTOS, H. P.; FONTANELI, R. S. Forrageiras para Integração Lavoura-Pecuária-Floresta na Região Sul-Brasileira. 2. ed. Brasília: Embrapa, 2012. 274p.

FLORES, R. Produção de forragem de populações de azevém anual no estado do Rio Grande do Sul. Revista Brasileira de Zootecnia, Porto Alegre, v. 37, n. 7, p.1168-1175, 2008.

FLOSS, E. L. Manejo forrageiro de aveia (Avena sp.) e azevém (Lolium SP). In: SIMPÓSIO SOBRE MANEJO DA PASTAGEM, 9., 1988, Piracicaba. Anais... Piracicaba: Fundação de Estudos Agrários Luiz de Queiroz, 1988. p.231268.

GARCIA, D. C; MENEZES, N. L. Teste de envelhecimento precoce para sementes de azevém, aveia preta e milheto. Ciência Rural, Santa Maria, v. 29, n. 2, p.233-237, 1999.
HESSEL, C. L. E.; VILLELA, F. A.; AUMONDE, T. Z.; PEDÓ, T. Mesa densimétrica e qualidade fisiológica de sementes de brachiária. Informativo ABRATES, Londrina, v.22, n. 3, p. 73-76, 2012.

HOLBIG, L. S.; HARTER, F. S.; GALINA, S.; DEUNER, C.; VILlELA, F. A. Diferenças na qualidade física e fisiológica de sementes de aveia preta e azevém comercializadas em duas regiões do Rio Grande do Sul. Revista da FZVA, Uruguaiana v.18, n.2, p.70-80, 2011.

MAIA, M. S. Secagem de sementes de azevém anual (Lolium multiflorum Lam.) com ar ambiente forçado. 1995. 108f. Tese (Doutorado em Fitotecnia) - Universidade Federal de Pelotas, Pelotas, 1995.

MARCHESAN, R. Produção e valor nutricional de cultivares de azevém consorciados ou não com aveia preta submetidos a dois resíduos de pastejo. 2014. 59f. Dissertação (Mestrado em Zootecnia) - Universidade Tecnológica Federal do Paraná. Dois Vizinhos, 2014.

MEDEIROS, R. B.; NABINGER, C. Rendimento de sementes de forragem de azevém em resposta a dose de nitrogênio e regime de corte. Revista Brasileira de Sementes, Londrina, v. 23, n. 2, p. 245-254, 2001.

NAKAGAWA, J. Testes de vigor baseados na avaliação de plântulas. In: KRZYZANOWSKI, F. C.; VIEIRA, R. D.; FRANÇA-NETO, J.B. (Eds.). Vigor de sementes: conceitos e testes. Londrina: ABRATES, 1999. p.2:1- 2:21.

OLIVEIRA, L. V.; FERREIRA, O. G. L.; COELHO, R. A. T.; FARIAS, P. P.; SILVEIRA, R. F. Características produtivas e morfofisiológicas de cultivares de azevém. Pesquisa Agropecuária Tropical, Goiânia, v. 44, n. 2, p.191-197, 2014.

ROSO, C.; RESTLE, J.; SOARES, A. B.; ALVES FILHO, D. C.; BRONDANI, I. L. Produção e qualidade de forragem da mistura de gramíneas anuais de estação fria sob pastejo contínuo. Revista Brasileira de Zootecnia, Viçosa, v.28, n.3, p.459-467, 1999.

TERNUS, R. M.; MENEGHELLO, G.; BREDA, M. L. E.; CAVALCANTE, J. A. O controle externo de qualidade na comercialização de sementes. Seed News, Pelotas, v. 20, n.2, p.18-23, 2016. 